\title{
Experimental Investigation on Wave Interaction with Horizontal Slotted Submerged Porous Breakwater
}

\author{
Rounak Afroz ${ }^{1}$, Md. Ataur Rahman ${ }^{1}$
}

\begin{abstract}
In this research work the interaction between waves and horizontal slotted submerged porous breakwater has been investigated experimentally. To investigate the performance of proposed horizontal slotted submerged breakwater, experimental studies are carried out in a two-dimensional wave flume $(21.3 \mathrm{~m}$ long, $0.76 \mathrm{~m}$ wide and $0.74 \mathrm{~m}$ deep) at the Hydraulics and River Engineering Laboratory of the Bangladesh University of Engineering and Technology. A set of experiments are carried out at $50 \mathrm{~cm}$ still water depth with fixed horizontal slotted submerged breakwaters of three different porosities $(\mathrm{n}=0.4,0.5$ and 0.6$)$ for interaction with regular waves of four different wave periods $(\mathrm{T}=1.6 \mathrm{sec}, 1.7 \mathrm{sec}$, $1.8 \mathrm{sec}$ and $2.0 \mathrm{sec}$ ) in the wave flume. For 12 run conditions, data of water surface at different locations are collected manually by providing a vertical scale on the flume side made of glass. Six different locations both in front of and behind the breakwater are selected for data collection. Different hydrodynamic co-efficient such as transmission co-efficient $\left(\mathrm{K}_{\mathrm{t}}\right)$, reflection co-efficient $\left(\mathrm{K}_{\mathrm{r}}\right)$ and wave energy loss co-efficient $\left(\mathrm{K}_{\mathrm{L}}\right)$ are determined from the measured water surface data for various run conditions. These co-efficient values were then, analyzed with respect to relative breakwater width (k.B), [where, $\mathrm{k}=$ wave number $(2 \pi / \mathrm{L}), \mathrm{B}=$ breakwater width] and porosity of breakwater. Experimental results reveal that, for transmitting smaller part of wave energy through the breakwater, minimum transmission co-efficient, $\mathrm{K}_{\mathrm{t}}=0.526$ was obtained for breakwater with the lowest porosity $(\mathrm{n}=0.4)$ for the shortest wave, i.e. $\mathrm{T}=1.6 \mathrm{sec}$. Minimum reflection co-efficient, $\mathrm{K}_{\mathrm{r}}=0.03448$ was obtained for breakwater with the highest porosity $(n=0.6)$ for the longest wave, i.e. $\mathrm{T}=2 \mathrm{sec}$. It is also seen that wave energy loss coefficient $\left(\mathrm{K}_{\mathrm{L}}\right)$ decreases from 0.68 to 0.47 with increasing porosity.
\end{abstract}

Keywords--Experimental investigation, horizontal slotted, submerged porous breakwater, hydrodynamic co-efficient

\section{INTRODUCTION}

Breakwaters are wave energy barriers designed to protect the land or near shore area behind them from the direct attack of waves. Breakwaters have traditionally been used only for harbor protection and navigational purposes; but in recent years, designs of shore-parallel segmented breakwaters have been used for shore protection purposes. Segmented breakwaters can be used to provide protection over longer sections of shoreline than is generally managed through the use of bulkheads or revetments. Wave energy is able to pass through the breakwater gaps, allowing for the maintenance of some level of longshore sediment transport, as well as mixing and flushing of the sheltered waters behind the structures.

${ }^{1}$ Bangladesh University of Engineering and Technology, Bangladesh
The dissipation of wave energy allows drift material to be deposited behind the breakwater. This accumulation of material protects the shore and may also extend the beach. The amount of deposition depends on the site characteristics and the design of the breakwater. Various aspects of two and three dimensional problems of wave interaction with submerged, bottom founded, or floating surface-piercing structures have been studied both numerically and experimentally by many investigators. Liao et al (2013) studied on the wave breaking criteria and energy loss caused by a submerged porous breakwater on a horizontal bottom. Jin et al (2013) analyzed the horizontal and vertical velocities of each later interface in the process of solitary wave propagation through submerged breakwater. Wu et al (2012) studied the interactions between a non breaking solitary wave and a submerged permeable breakwater experimentally and numerically. Wiryanto (2011) analyzed the wave propagation passing over the submerged breakwater for monochromatic and solitary waves. Rahman and Womera (2013) investigated the interaction between waves and rectangular submerged impermeable breakwater. To predict the investigation, a twodimensional numerical model based on the SOLA-VOF method was proposed there. Rahman and Akter (2014) investigated the efficiency of the porous breakwaters governed by their porosity and their depth of submergence. In this study experimental investigations are carried out in a twodimensional wave flume at the Hydraulics and River Engineering Laboratory of the Bangladesh University of Engineering and Technology to investigate the hydrodynamic performance of proposed rectangular type submerged porous breakwater.

\section{EXPERIMENTAL INVESTIGATION}

To investigate the hydrodynamic performance of proposed rectangular shaped horizontal slotted submerged porous breakwater, experimental studies are carried out in a two-dimensional wave flume $(21.3 \mathrm{~m}$ long, $0.76 \mathrm{~m}$ wide and $0.74 \mathrm{~m}$ deep) at the Hydraulics and River Engineering Laboratory of the Bangladesh University of Engineering and Technology. In $21.3 \mathrm{~m}$ long wave flume, the wave generator is placed at $190 \mathrm{~cm}$ downstream from the upstream end of the flume. The submerged porous breakwater is installed at a distance of $800 \mathrm{~cm}$ from the wave generator. Six different positions are chosen to collect the data of water surface elevation. Three locations are in front of the submerged porous breakwater to investigate the incident wave properties. The fourth position of data collection is set over the breakwater. Then the last two positions are chosen behind the breakwater to observe the effect of breakwater installation in 
reduction of wave height. The first position of data collection is at $400 \mathrm{~cm}$ in front of the breakwater. The other positions are at equidistance of $100 \mathrm{~cm}$ from each other. Then finally at the end of the flume a wave absorber of $245 \mathrm{~cm}$ length is installed. The detail of experimental setup is shown in Fig 1.

Location for measuring water surface

elevation

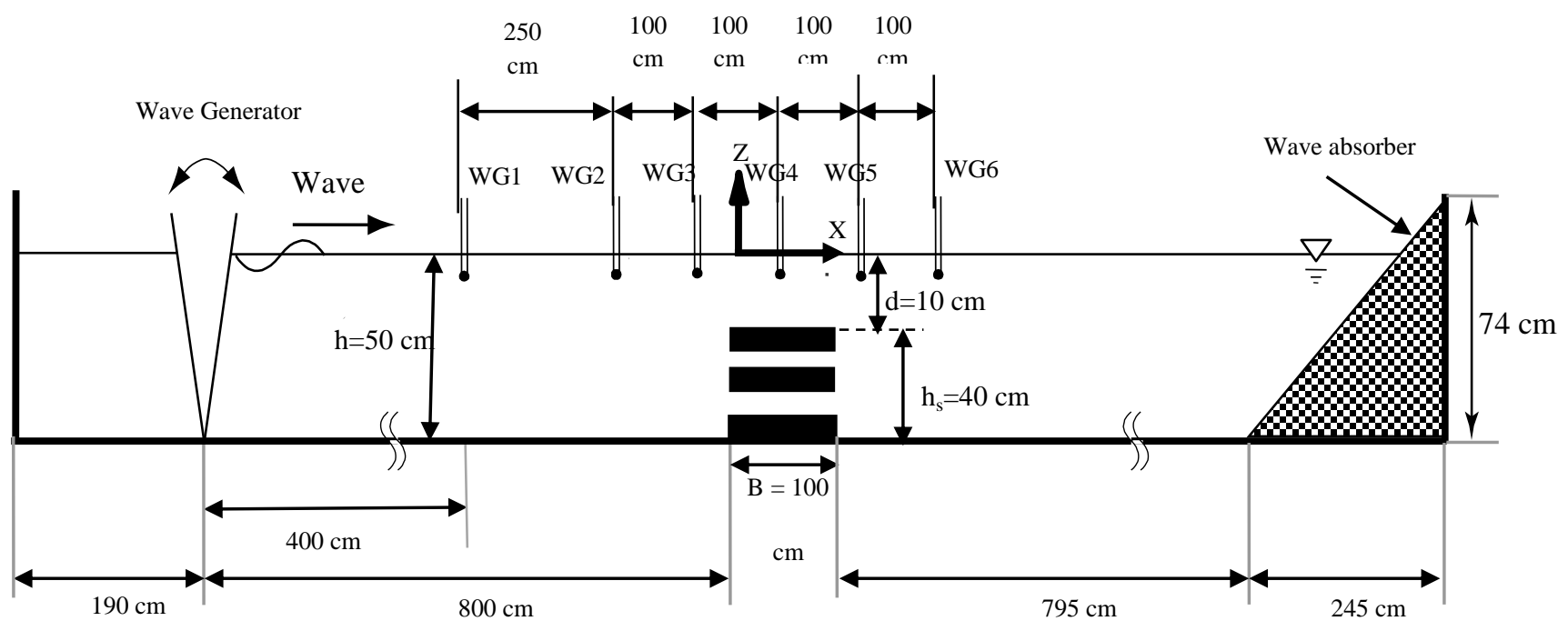

Fig 1: Detail of the experimental setup

\section{A. Experimental Results}

\section{i. $\quad$ Variation of $\eta / H i$ with $t / T$}

Variation of water surface ( $\eta$ ) of transmitted wave (measured at location WG6 behind the breakwater) with time (t) is shown in the non-dimensional form as variation of $\eta / \mathrm{H}_{i}$ with $\mathrm{t} / \mathrm{T}$ in Fig 2 . For wave period $\mathrm{T}=1.6 \mathrm{sec}$, the incident wave height $\mathrm{H}_{\mathrm{i}}=9.5 \mathrm{~cm}$ is reduced after breaking due to breakwater installation. When the breakwater porosity is $\mathrm{n}=0.4$, the incident wave height is $47.4 \%$ reduced. For installation of breakwater of $n=0.5$ porosity, the wave height is reduced to $44 \%$ of the incident wave height. When the breakwater porosity is $n=0.6,35.71 \%$ wave height is reduced due to wave breaking. Similar trend is also found for other wave periods.

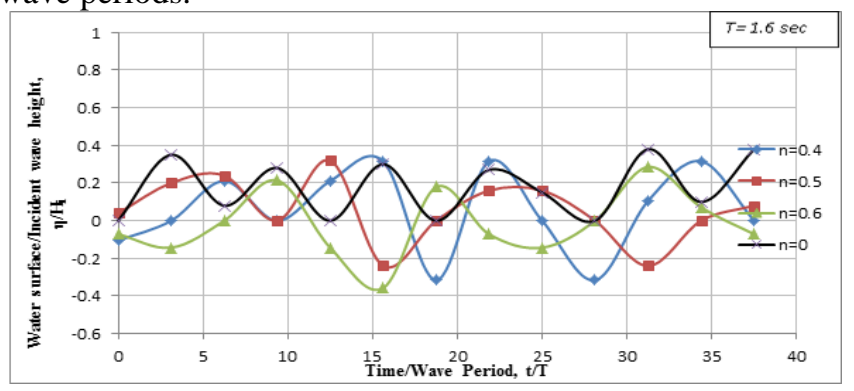

Fig 2: Variation of $\eta / H i$ with $t / T$ for different wave periods

\section{ii.Effect of porosity on the wave reflection coefficient $\left(K_{r}\right)$}

Fig 3 presents the relationship between the wave reflection coefficient $\left(\mathrm{K}_{\mathrm{r}}\right)$ and the relative breakwater width $(\mathrm{k} . \mathrm{B}=2 \mathrm{~B} \pi / \mathrm{L})$, for $\mathrm{n}=0.4,0.5$ and 0.6 , where $\mathrm{k}$ is the wave number $(2 \pi / L), B$ is the breakwater width and $L$ is the wave length.

The figure shows that, $K_{r}$ increases as relative breakwater width k.B increases. This may be attributed to the increase of the wave energy loss as the width of the porous media increases. Also, the reflection coefficient $\left(\mathrm{K}_{\mathrm{r}}\right)$ decreases as porosity increases.

\section{iii. Effect of Porosity on the wave transmission coefficient $\left(K_{t}\right)$}

Fig 4 presents the relationship between the transmission coefficient $\left(\mathrm{K}_{\mathrm{t}}\right)$ and the relative breakwater width k.B. The figure shows that, the transmission coefficient $\left(\mathrm{K}_{\mathrm{t}}\right)$ decreases as k.B increases. This means that, the wide breakwater reduces the transmitted waves more as compared to narrow breakwater. 


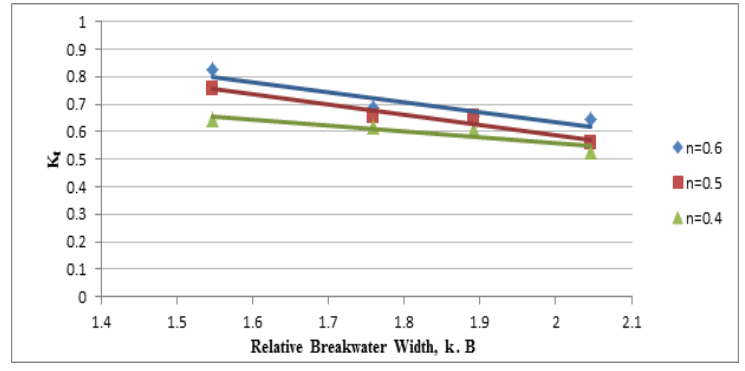

Fig 3: Effect of breakwater porosity on the reflection coefficient

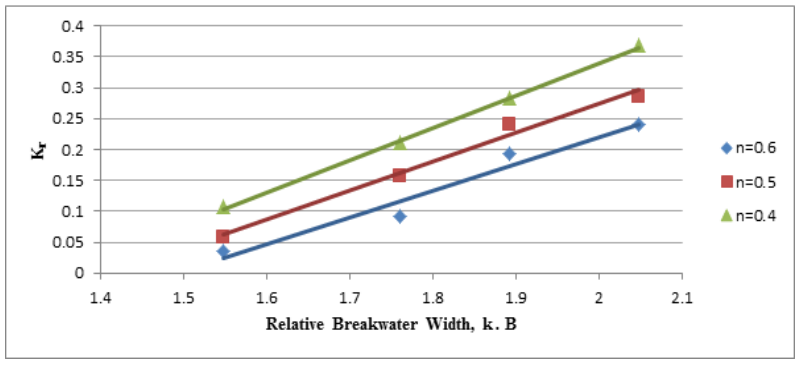

Fig 4: Effect of breakwater porosity on the transmission coefficient

The above mentioned behavior could be attributed to two reasons. First, the increase of the breakwater width causes the increase of the friction between the breakwater surface and the transmitted waves, causing more loss of wave energy. Second, as the wave becomes short, the water particle velocity and acceleration face changes and the turbulence caused due to these changes cause dissipation in the wave energy.

iv. Effect of Porosity on the wave energy loss coefficient $\left(K_{L}\right)$

Fig 5 presents the relationship between the wave energy loss coefficient $\left(\mathrm{K}_{\mathrm{L}}\right)$ and the relative breakwater width k.B for $\mathrm{n}=0.4,0.5$ and 0.6. These figures show that, $\mathrm{K}_{\mathrm{L}}$ increases as k.B increases. Also the wave energy loss coefficient $\left(\mathrm{K}_{\mathrm{L}}\right)$ increases as the porosity decreases. Hence it can be said from the above results that, wave energy loss coefficient is higher for less porous structure. This is due to the fact that most of the wave energy can be transmitted through the highly porous structure. That's why the wave transmission coefficient is greater for this kind of structure

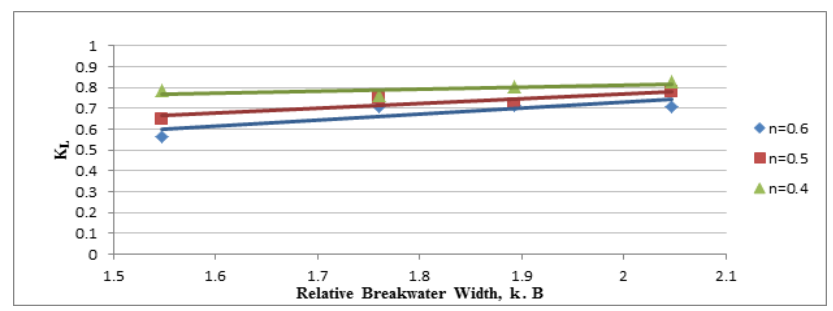

Fig 5: Effect of breakwater porosity on the wave energy loss coefficient

\section{CONCLUSIONS}

From this study the following conclusions can be derived:

(a) The functional efficiency of horizontal slotted submerged porous breakwater is measured by wave reflection, transmission and wave energy loss co-efficient. From the experimental data analysis it can be concluded that wave reflection coefficient $\left(\mathrm{K}_{\mathrm{r}}\right)$ increases as relative breakwater width (k.B) increases (k.B=2B $\pi / L$, where $k$ is the wave number). Also, the reflection coefficient $\left(\mathrm{K}_{\mathrm{r}}\right)$ decreases as porosity $(\mathrm{n})$ increases. The transmission coefficient $\left(\mathrm{K}_{\mathrm{t}}\right)$ decreases as relative breakwater width k.B increases. This means that, the breakwater reduces the transmitted waves as the breakwater width (B) increases or the wave length (L) decreases. Wave energy loss coefficient, $\mathrm{K}_{\mathrm{L}}$ increases as relative breakwater width k.B increases. Also the wave energy loss coefficient $\left(\mathrm{K}_{\mathrm{L}}\right)$ increases as the porosity decreases.

(b) The transmission coefficient $\left(\mathrm{K}_{\mathrm{t}}\right)$ is found minimum for minimum porosity of $\mathrm{n}=0.4$ which is 0.5263 and increased to 0.6428 with the increasing porosity of $n=0.6$. Also the wave energy loss coefficient $\left(\mathrm{K}_{\mathrm{L}}\right)$ is found maximum for minimum porosity of $n=0.4$ which is 0.8288 and decreased to 0.7107 with the increasing porosity of $\mathrm{n}=0.6$. So in some important coastal areas where full dissipation of wave energy is not required, horizontal slotted submerged porous breakwater of porosity $\mathrm{n}=0.4$ can be used efficiently in those areas, as almost $83 \%$ of energy is dissipated by this breakwater. Thus, the submerged porous breakwater would be an excellent option for coastal soft defense structures that are able to enhance water circulation and exchange between open sea and sheltered areas.

Acknowledgement: The authors are grateful to NufficNICHE BGD 155 Project of Department of Water Resources Engineering (DWRE), BUET for funding the research work

\section{REFERENCES}

[1] Jin. W, Qi-hua. Z, Deng-ting. W, Shukrieva. S. (2013). "Solitary Wave Propagation Influenced by Submerged Breakwater", Chaina Ocean Eng., Vol. 27(5), pp. 593-604 https://doi.org/10.1007/s13344-013-0050-8

[2] Liao, Y. C., Jiang, J. H., Wu, Y. P., \& Lee, C. P. (2013). "Experimental Study of Wave Breaking Criteria and Energy Loss Caused by a Submerged Porous Breakwater on Horizontal Bottom", Journal of Marine Science and Technology, Vol. 21(1), pp. 35-41.

[3] Rahman, M.A. and Akter, A. (2014). "The effect of porosity of submerged and emerged breakwater on wave transmission", International Journal of Environmental Science and Development, Vol. 5(5), pp. 473-478 https://doi.org/10.7763/IJESD.2014.V5.530

[4] Rahman, M.A. and Womera , S.A. (2013). "Experimental and Numerical Investigation on Wave Interaction with Submerged Breakwater", Journal of Water Resources and Ocean Science, Vol. 2(6), pp. 155-164 https://doi.org/10.11648/j.wros.20130206.11

[5] Wu, Y. T., Hsiao, S. C., \& Chen, G. S. (2012). "Solitary wave interaction with a submerged permeable breakwater: experiment and numerical modeling", Coastal Engineering Proceedings, Vol. 1(33), pp.30.

https://doi.org/10.9753/icce.v33.structures.30 
[6] Wiryanto, L. H. (2011). "Wave propagation passing over a submerged porous breakwater", Journal of Engineering Mathematics, Vol.70(13),pp.129-136.

https://doi.org/10.1007/s10665-010-9419-3

About Author (s):

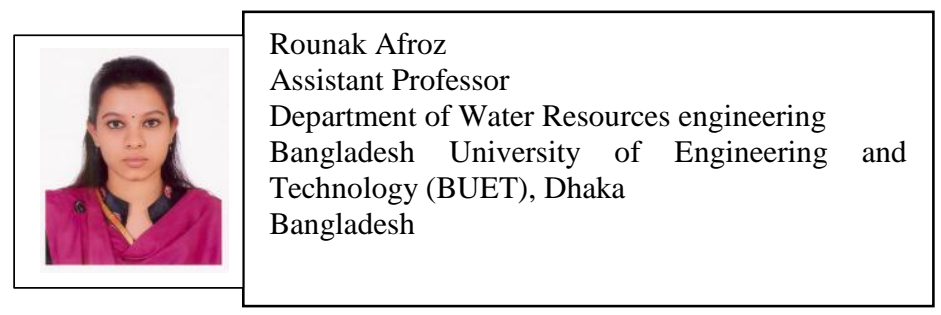

\begin{tabular}{|l|l|} 
Dr. Md. Ataur Rahman \\
Professor \\
Department of Water Resources engineering \\
Bangladesh University of Engineering and \\
Technology (BUET), Dhaka \\
Bangladesh
\end{tabular}

